\title{
Prognostic significance of the combination of preoperative red cell distribution width and platelet distribution width in patients with gastric cancer
}

\author{
Hiroaki Saito ${ }^{1,2^{*}}$, Shota Shimizu ${ }^{2}$, Yuji Shishido ${ }^{2}$, Kozo Miyatani $^{2}$, Tomoyuki Matsunaga ${ }^{2}$ and Yoshiyuki Fujiwara $^{2}$
}

\begin{abstract}
Background: Platelet distribution width (PDW) and red cell distribution width (RDW) are readily obtainable data, and are reportedly useful as prognostic indicators in some cancers. However, their prognostic significance is unclear in gastric cancer (GC).

Methods: We enrolled 445 patients with histopathological diagnoses of gastric adenocarcinoma who had undergone curative surgeries.

Results: According to the optimal cut-off value of PDW and RDW by receiver operating characteristic (ROC) analysis, we divided patients into PDW ${ }^{\text {High }}(\geq 16.75 \%)$, PDW ${ }^{\text {Low }}(<16.75 \%)$, RDW $^{\text {High }}(\geq 14.25 \%)$, and RDW ${ }^{\text {Low }}(<14.25 \%)$ subgroups. Overall survival (OS) was significantly worse in patients with PDW ${ }^{\text {High }}$ than in those with PDW ${ }^{\text {Low }}(P=0.0015)$, as was disease specific survival $(P=0.043)$. OS was also significantly worse in patients with $\mathrm{RDW}^{\text {High }}$ than in those with $\operatorname{RDW}^{\text {Low }}(P<0.0001)$, as was disease specific survival $(P=0.0002)$. Multivariate analysis for OS revealed that both PDW and RDW were independent prognostic indicators. Patients were then given PDW-RDW score by adding points for their different subgroups (1 point each for PDW ${ }^{\text {High }}$ and RDW ${ }^{\text {High }}$; 0 points for PDW ${ }^{\text {Low }}$ and RDW ${ }^{\text {Low }}$ ). OS significantly differed by PDW-RDW score $(P<0.0001)$, as did disease specific survival $(P=0.0005)$. In multivariate analysis for OS, PDW-RDW score was found to be an independent prognostic indicator.
\end{abstract}

Conclusions: The prognosis of GC patients can be precisely predictable by using both PDW and RDW.

Keywords: Gastric cancer, Platelet distribution width, Prognosis, Recurrence, Red cell distribution width

\section{Background}

Recently, there has been growing interest in developing prognostic indicators for various cancers using hematological and serologic parameters, which can be obtained easily and less invasively. Since complete blood count $(\mathrm{CBC})$ data is easily obtainable data in routine clinical

\footnotetext{
${ }^{*}$ Correspondence: sai10@tottori-med.jrc.or.jp

1 Department of Surgery, Japanese Red Cross Tottori Hospital, 117

Shotoku-cho, Tottori 680-8517, Japan

Full list of author information is available at the end of the article
}

setting, many prognostic indicators, including neutrophil to lymphocyte ratio and platelet to lymphocyte ratio, have been developed using $\mathrm{CBC}$ data thus far.

Platelet distribution width (PDW) and red cell distribution width (RDW) are also data that can be obtained from CBC. PDW shows variation of platelet size distribution and is used to evaluate platelet morphology and activation [1, 2]. A recent study revealed close correlation among PDW, white blood cell count, and serum C-reactive protein level, indicating that PDW also reflect inflammation status [3]. The RDW shows the 
heterogeneity in erythrocyte size and is widely used as parameter for anemia [4]. Chronic inflammation and poor nutrition are thought to increase RDW, indicating that RDW also reflect inflammation and nutritional status [5-7]. Because both inflammation and nutritional status are reportedly associated with cancer prognosis, PDW and RDW are being recently studied as prognostic indicators for cancer patients.

Gastric cancer (GC) is the fifth leading cause of cancer deaths worldwide [8]. Although there are a few reports showing the prognostic significance of either PDW or RDW alone in GC patients, the prognostic significance of the combination of PDW and RDW has not been reported thus far. Because both PDW and RDW are obtainable from preoperative $\mathrm{CBC}$ data, the combination of PDW and RDW might provide useful prognostic information in managing GC patients including treatment strategy preoperatively. Here we conducted this study to answer this question.

\section{Methods}

\section{Patients}

A total of 445 gastric cancer patients who underwent gastrectomy at Tottori University Hospital between January 2005 and December 2013 were included in this study. The inclusion criteria were as follows: patients (1) with newly histologically confirmed gastric adenocarcinoma; and (2) underwent curative gastrectomy (R0 resection). The exclusion criteria were as follows: patients (1) had synchronous or metachronous cancer in other organs; (2) underwent neoadjuvant chemotherapy; and (3) without complete medical records and available follow-up data. The Japanese Classification of Gastric
Carcinoma was used to determine their clinicopathologic findings [9]. The number of patients were 310, 82 , and 53 in stage I, II, and IIII, respectively. Patients periodically visited outpatient clinics to take blood test including tumor marker and diagnostic imaging, such as esophagogastroduodenoscopy, ultrasonography, and computed tomography, for early detection of recurrence. PDW, RDW, serum level of carcinoembryonic antigen (CEA), and platelet count (PC) in the peripheral blood, which were measured within 1 month before operation, patterns of recurrence, and causes of death were obtained through review of the hospital database. For the measurement of PDW and RDW, blood samples were collected in tubes containing dipotassium ethylenediaminetetraacetic acid as an anti-coagulant and analyzed immediately after collection.

\section{Statistical analysis}

The chi-squared test was used to determine the differences in clinicopathologic characteristics between groups. The optimal cutoffs for preoperative RDW and PDW in the survival analysis were determined using the receiver operating characteristic (ROC) analysis. In the survival analysis, OS refers to the time which begins at operation and up to the time of death. All causes of death are included to calculate OS. The disease specific survival (DSS) was defined as the interval between surgery and the date of death from gastric cancer. Therefore, the deaths not caused by gastric cancer were considered as lost to follow-up as of time of death for the statistical analysis of disease specific survival rate. Survival curves were constructed using Kaplan-Meier method. Their differences were determined using the (a)

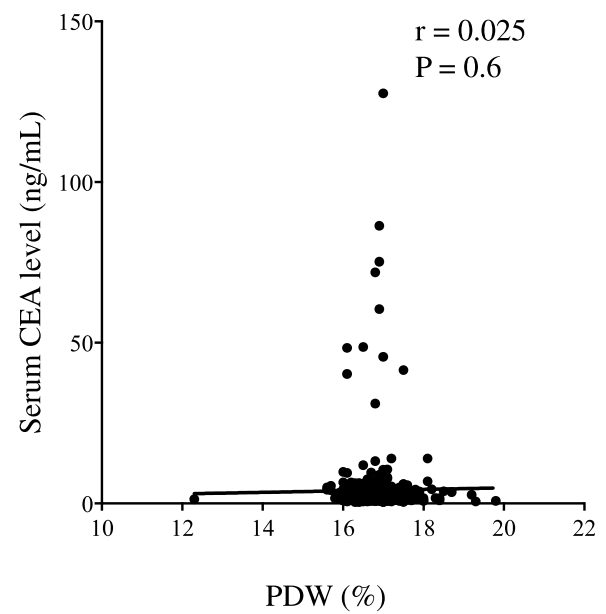

(b)

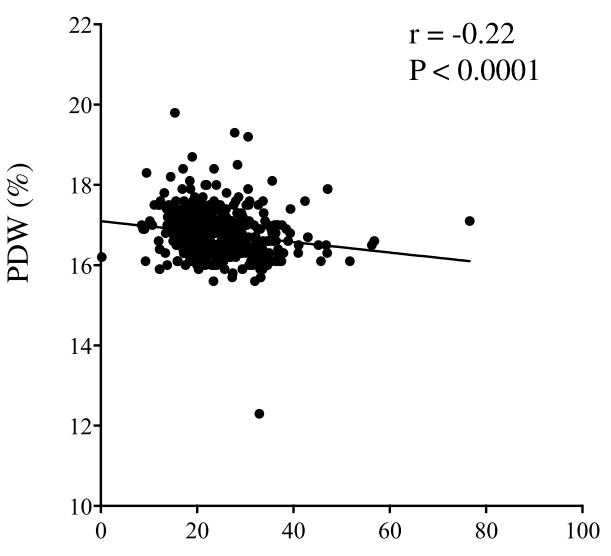

Platelet count $(\mathrm{x} 104 / \mu \mathrm{L})$

Fig. 1 a Platelet distribution width (PDW) and serum CEA level were not significantly correlated $(r=0.025, P=0.6)$; however (b), PDW and peripheral platelet count (PC) were significantly but weakly correlated $\left(r={ }^{-} 0.22, P<0.0001\right)$ 
log-rank test. Multivariate analysis was performed using Cox's proportional hazards model and a stepwise procedure. The covariates included in this study are age, gender, tumor size, histology, depth of invasion, lymph node metastasis, lymphatic invasion, vascular invasion, approach (open or laparoscopy), type of gastrectomy, lymph node dissection, adjuvant chemotherapy, PDW, and RDW. $P<0.05$ was considered statistically significant. GraphPad Prism (GraphPad Software, Inc., La Jolla, CA, USA) and Stat View (Abacus Concepts, Inc., Berkeley, CA, USA) software were used for the statistical analyses.

Table 1 Comparison of patient characteristics versus preoperative platelet distribution width (PDW)

\begin{tabular}{|c|c|c|c|}
\hline Variables & $\mathrm{PDW}^{\mathrm{High}}(n=219)$ & $\mathrm{PDW}^{\text {Low }}(n=226)$ & $P$ value \\
\hline Age (years) & & & 0.0014 \\
\hline$<70(n=217)$ & $90(41.5 \%)$ & $127(58.5 \%)$ & \\
\hline$\geq 70(n=228)$ & $129(56.6 \%)$ & $99(43.4 \%)$ & \\
\hline Gender & & & 0.23 \\
\hline Male $(n=328)$ & 167 (50.9\%) & $161(49.1 \%)$ & \\
\hline Femal $(n=117)$ & $52(44.4 \%)$ & $65(55.6 \%)$ & \\
\hline Tumor size (cm) & & & 0.52 \\
\hline$<4(n=281)$ & $135(48.0 \%)$ & $146(52.0 \%)$ & \\
\hline$\geq 4(n=164)$ & $84(51.2 \%)$ & $80(48.8 \%)$ & \\
\hline Histology ${ }^{a}$ & & & 0.059 \\
\hline Differentiated $(n=244)$ & $130(53.3 \%)$ & $114(46.7 \%)$ & \\
\hline Undifferentiated $(n=201)$ & $89(44.3 \%)$ & $112(55.7 \%)$ & \\
\hline Depth of invasion ${ }^{b}$ & & & 0.96 \\
\hline $\mathrm{T} 1(n=284)$ & 140 (49.3\%) & $144(50.7 \%)$ & \\
\hline $\mathrm{T} 2 / 3 / 4(n=161)$ & $79(49.1 \%)$ & $82(50.9 \%)$ & \\
\hline Lymph node metastasis & & & 0.6 \\
\hline Absent $(n=342)$ & $166(48.5 \%)$ & $176(51.5 \%)$ & \\
\hline Present $(n=103)$ & $53(51.5 \%)$ & $50(48.5 \%)$ & \\
\hline Lymphatic invasion & & & 0.5 \\
\hline Absent $(n=186)$ & $88(47.3 \%)$ & $98(52.7 \%)$ & \\
\hline Present $(n=259)$ & $131(50.6 \%)$ & $128(49.4 \%)$ & \\
\hline Vascular invasion & & & 0.88 \\
\hline Absent $(n=232)$ & $115(49.6 \%)$ & $117(50.4 \%)$ & \\
\hline Present $(n=213)$ & $104(48.8 \%)$ & 109 (51.2\%) & \\
\hline Stage of disease & & & 0.77 \\
\hline I $(n=310)$ & $154(49.7 \%)$ & $156(50.3 \%)$ & \\
\hline$\|/\|(n=135)$ & $65(48.1 \%)$ & $70(51.9 \%)$ & \\
\hline Approach & & & 0.77 \\
\hline Open $(n=257)$ & $129(50.2 \%)$ & $128(49.8 \%)$ & \\
\hline Laparoscopy $(n=188)$ & $90(47.9 \%)$ & $98(52.1 \%)$ & \\
\hline Gatrectomy (total vs. distal and proximal partial) & & 0.073 & \\
\hline Total $(n=95)$ & $39(41.1 \%)$ & $56(58.9 \%)$ & \\
\hline Distal or proximal $(n=350)$ & $180(51.4 \%)$ & $170(48.6 \%)$ & \\
\hline Lymph node dissection & & & 0.76 \\
\hline $\mathrm{D} 0 / \mathrm{D} 1(n=312)$ & $155(49.7 \%)$ & $157(50.3 \%)$ & \\
\hline $\mathrm{D} 2(n=133)$ & $64(48.1 \%)$ & $69(51.9 \%)$ & \\
\hline Adjuvant chemotherpy & & & 0.36 \\
\hline Absent $(n=377)$ & $189(50.1 \%)$ & $188(49.9 \%)$ & \\
\hline Present $(n=68)$ & $30(44.1 \%)$ & $38(55.9 \%)$ & \\
\hline
\end{tabular}

a Differentiated or undifferentiated; Differentiated, papillary or tubular adenocarcinoma; undifferentiated, poorly differentiated or mucinous adenocarcinoma, or signet-ring cell carcinoma

${ }^{\mathrm{b}}$ Depth of invasion: $\mathrm{T} 1$, tumor invasion of the lamina propria or submucosa; $\mathrm{T} 2$, tumor invasion of the muscularis propria; $\mathrm{T} 3$, tumor invasion of the subserosa; $\mathrm{T} 4$, tumor penetration of the serosa or tumor invasion of adjacent organs 


\section{Results}

The mean PDW was $16.78 \%$ (range: $12.30-19.8 \%$ ). Figure 1 shows the correlation among PDW, CEA and PC. PDW and CEA were not significantly correlated $(r=0.025 ; P=0.6)$; however, $\mathrm{PDW}$ and $\mathrm{PC}$ were significantly but weakly correlated $\left(r={ }^{-} 0.22 ; P<0.0001\right)$. ROC curve for OS status revealed the area under the curve (AUC) of PDW was higher than that of PC, which indicates that $\mathrm{PDW}$ is a better prognostic indicator than PC for GC patients. Because ROC analysis for OS indicated that the optimal cut-off value of PDW was $16.75 \%$ (AUC $=0.583, P=0.011$ ), we divided patients into $\mathrm{PDW}^{\text {High }}(\geq 16.75 ; n=219)$ and $\mathrm{PDW}^{\text {Low }}(<16.75$; $n=226$ ). Table 1 shows the correlation between preoperative PDW and patients' clinicopathological variables. Preoperative PDW ${ }^{\text {High }}$ was significantly more common in elderly patients ( $\geq 70$ years) than in non-elderly patients ( $<70$ years; $P=0.0014$ ). OS was significantly worse in patients with $\mathrm{PDW}^{\text {High }}$ than in those with $\mathrm{PDW}^{\text {Low }}$ $(P=0.0015$, Fig. $2 \mathrm{a})$, as was DSS $(P=0.043$, Fig. $2 \mathrm{~b})$.

Because ROC analysis for OS indicated that the optimal cut-off value of RDW was $14.25 \%$ (AUC $=0.651, P<0.0001$ ), we divided patients into $\mathrm{RDW}^{\mathrm{High}}(\geq 14.25 ; n=149)$ and RDW $^{\text {Low }}(<14.25 \% ; n=296)$. Table 2 shows the correlation between preoperative RDW and patients' clinicopathological variables. Preoperative RDW ${ }^{\mathrm{High}}$ was significantly more common in elderly patients, those with larger tumors, and those with vascular invasion than in non-elderly patients $(P=0.0032)$, those with smaller tumors $(P=0.0004)$, and those without vascular invasion $(P=0.011)$, respectively. OS was significantly worse in patients with RDW ${ }^{\text {High }}$ than in those with $\mathrm{RDW}^{\text {Low }}(P<0.0001$, Fig. 3a), as was DSS
$(P=0.0002$, Fig. $3 \mathrm{~b})$. Univariate analysis revealed that age, tumor size, depth of invasion, lymph node metastasis, lymphatic invasion, vascular invasion, approach, type of gastrectomy, lymph node dissection, adjuvant chemotherapy, preoperative PDW and RDW were significantly associated with OS. In multivariate analysis for OS, both PDW and RDW were independent prognostic indicators in GC patients, along with age, approach, lymph node metastasis, and vascular invasion (Table 3).

As we saw no correlation between preoperative PDW and RDW ( $r=0.06 ; P=0.21$; Fig. 4 ), we thought the combination of PDW and RDW might be more useful than either indicator used separately. Patients were then given PDW-RDW scores by adding points for their different subgroups (1 point each for PDW ${ }^{\text {High }}$ and RDW ${ }^{\text {High }}$; 0 points for PDW ${ }^{\text {Low }}$ and $\left.R D W^{\text {Low }}\right)$. OS significantly differed by PDW-RDW score $(P<0.0001$, Fig. $5 \mathrm{a})$, as did DSS $(P=0.0005$, Fig. $5 b)$. In multivariate analysis for OS, PDW-RDW score was found to be an independent prognostic indicator (Table 4).

\section{Discussion}

Platelets have some pro-tumor effects and play significant roles in cancer progression and metastasis. They produce platelet derived endothelial cell growth factor (PD-ECGF) [10]. PD-ECGF was a well-described angiogenetic factor and reported to enhance neoangionenesis at tumor site, which promote tumor growth and metastases. Platelets also form aggregates with tumor cells in circulation, facilitating their adhesion to the vascular endothelium, which results in enhancement of metastasis, since tumor cell adhesion to the vascular endothelium is the important step

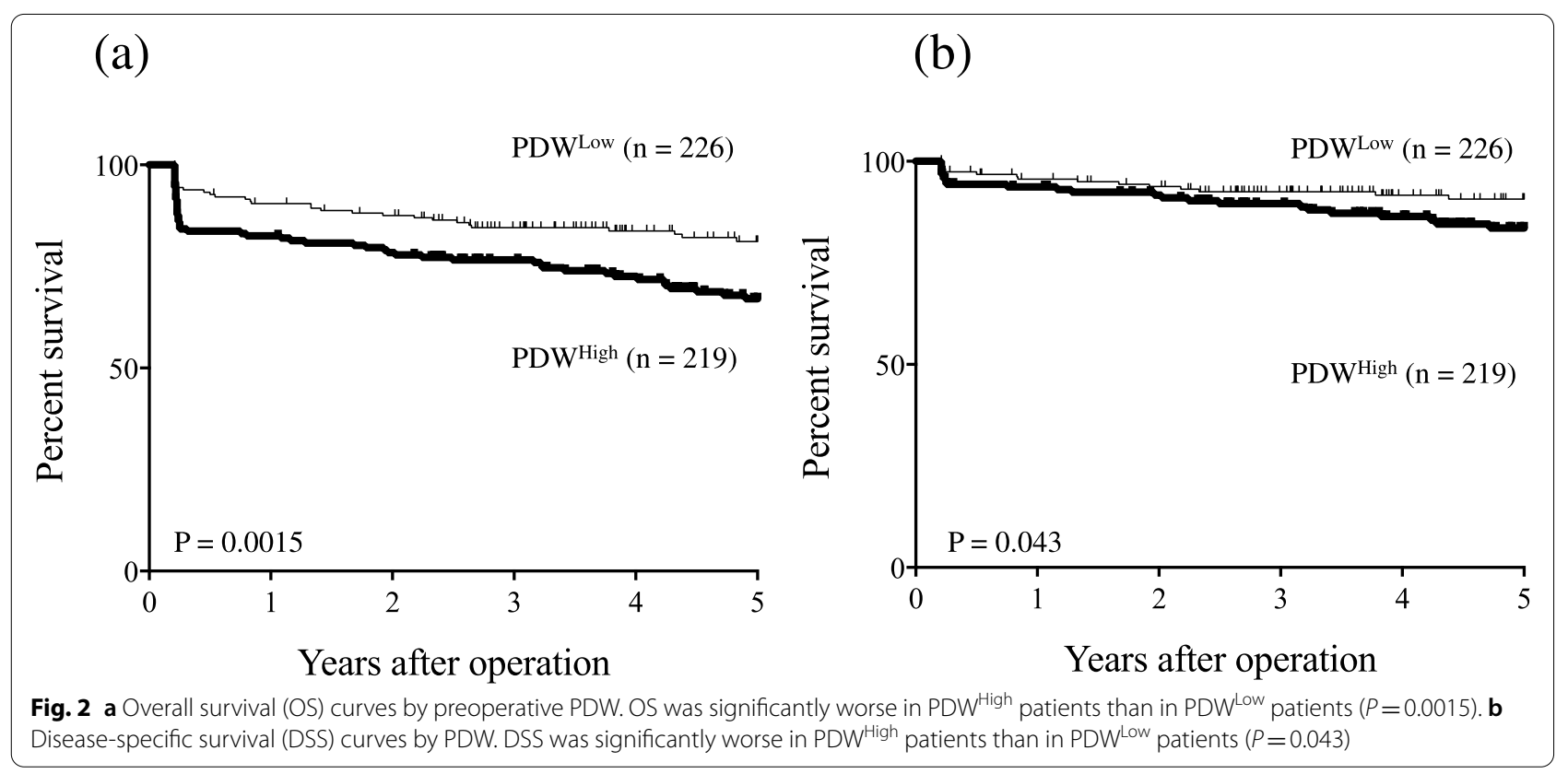


Table 2 Comparison of patient characteristics versus preoperative red cell distribution width (RDW)

\begin{tabular}{|c|c|c|c|}
\hline Variables & $\mathrm{RDW}^{\mathrm{High}}(n=149)$ & $\mathrm{RDW}^{\text {Low }}(n=296)$ & $P$ value \\
\hline \multicolumn{3}{|l|}{ Age (years) } & \multirow[t]{3}{*}{0.0032} \\
\hline$<70(n=217)$ & $58(26.7 \%)$ & $159(73.3 \%)$ & \\
\hline$\geq 70(n=228)$ & 91 (39.9\%) & $137(60.1 \%)$ & \\
\hline \multicolumn{3}{|l|}{ Gender } & \multirow[t]{3}{*}{0.47} \\
\hline Male $(n=328)$ & $113(34.5 \%)$ & $215(65.5 \%)$ & \\
\hline Femal $(n=117)$ & $36(30.8 \%)$ & $81(69.2 \%)$ & \\
\hline \multicolumn{3}{|l|}{ Tumor size (cm) } & \multirow[t]{3}{*}{0.0004} \\
\hline$<4(n=281)$ & $77(27.4 \%)$ & $204(72.6 \%)$ & \\
\hline$\geq 4(n=164)$ & $72(43.9 \%)$ & $92(56.1 \%)$ & \\
\hline \multicolumn{3}{|l|}{ Histology } & \multirow[t]{3}{*}{0.39} \\
\hline Differentiated $(n=244)$ & $86(35.2 \%)$ & $158(64.8 \%)$ & \\
\hline Undifferentiated $(n=201)$ & $63(31.3 \%)$ & $138(68.7 \%)$ & \\
\hline \multicolumn{3}{|l|}{ Depth of invasion ${ }^{a}$} & \multirow[t]{3}{*}{0.057} \\
\hline $\mathrm{T} 1(n=284)$ & $86(30.3 \%)$ & $198(69.7 \%)$ & \\
\hline $\mathrm{T} 2 / 3 / 4(n=161)$ & $63(39.1 \%)$ & $98(60.9 \%)$ & \\
\hline \multicolumn{3}{|l|}{ Lymph node metastasis } & \multirow[t]{3}{*}{0.55} \\
\hline Absent $(n=342)$ & $112(32.7 \%)$ & $230(67.3 \%)$ & \\
\hline Present $(n=103)$ & 37 (35.9\%) & $66(64.1 \%)$ & \\
\hline \multicolumn{3}{|l|}{ Lymphatic invasion } & \multirow[t]{3}{*}{0.059} \\
\hline Absent $(n=186)$ & $53(28.5 \%)$ & $133(71.5 \%)$ & \\
\hline Present $(n=259)$ & $96(37.1 \%)$ & $163(62.9 \%)$ & \\
\hline \multicolumn{3}{|l|}{ Vascular invasion } & \multirow[t]{3}{*}{0.011} \\
\hline Absent $(n=232)$ & $65(28.0 \%)$ & $167(72.0 \%)$ & \\
\hline Present $(n=213)$ & $84(39.4 \%)$ & $129(60.6 \%)$ & \\
\hline \multicolumn{3}{|l|}{ Stage of disease } & \multirow[t]{3}{*}{0.54} \\
\hline I $(n=310)$ & $101(32.6 \%)$ & $209(67.4 \%)$ & \\
\hline$\|/\| I(n=135)$ & $48(35.6 \%)$ & $87(64.4 \%)$ & \\
\hline \multicolumn{3}{|l|}{ Approach } & \multirow[t]{3}{*}{0.16} \\
\hline Open $(n=257)$ & $93(36.2 \%)$ & $164(63.8 \%)$ & \\
\hline Laparoscopy $(n=188)$ & $56(29.8 \%)$ & $132(70.2 \%)$ & \\
\hline \multicolumn{3}{|c|}{ Gatrectomy (total vs. distal and proximal partial) } & \multirow[t]{3}{*}{0.13} \\
\hline Total $(n=95)$ & $38(40.0 \%)$ & $57(60.0 \%)$ & \\
\hline Distal or proximal $(n=350)$ & $111(31.7 \%)$ & $239(68.3 \%)$ & \\
\hline \multicolumn{3}{|l|}{ Lymph node dissection } & \multirow[t]{3}{*}{0.92} \\
\hline $\mathrm{D} 0 / \mathrm{D} 1(n=312)$ & $104(33.3 \%)$ & $208(66.7 \%)$ & \\
\hline $\mathrm{D} 2(n=133)$ & $45(33.8 \%)$ & $88(66.2 \%)$ & \\
\hline \multicolumn{3}{|l|}{ Adjuvant chemotherpy } & \multirow[t]{3}{*}{0.14} \\
\hline Absent $(n=377)$ & $121(32.1 \%)$ & $256(67.9 \%)$ & \\
\hline Present $(n=68)$ & $28(41.2 \%)$ & $40(58.8 \%)$ & \\
\hline
\end{tabular}

See Table 1 for histology and the depth of invasion

for the formation of metastasis by tumor cells $[11,12]$. Considering these pro-tumor effects of platelets, it is likely that platelet-related markers are useful prognostic indicators. In fact, the prognostic significance of $\mathrm{PC}$ has been reported in various cancers, including GC, thus far [13-17].

PDW is another platelet-related marker. Inflammation cytokines play essential roles in the development of inflammatory microenvironments in cancer, which contributes to the process of the tumor progression and metastasis. Excessive pro-inflammatory cytokines interfere with megakaryopoiesis, leading to an increased production of small-sized platelets from the bone marrow [18]. We previously demonstrated that the serum inflammation cytokine interleukin-6 (IL-6) level was significantly higher in the GC patients than in the healthy subjects [19]. Therefore, it is likely that PDW increases 
(a)

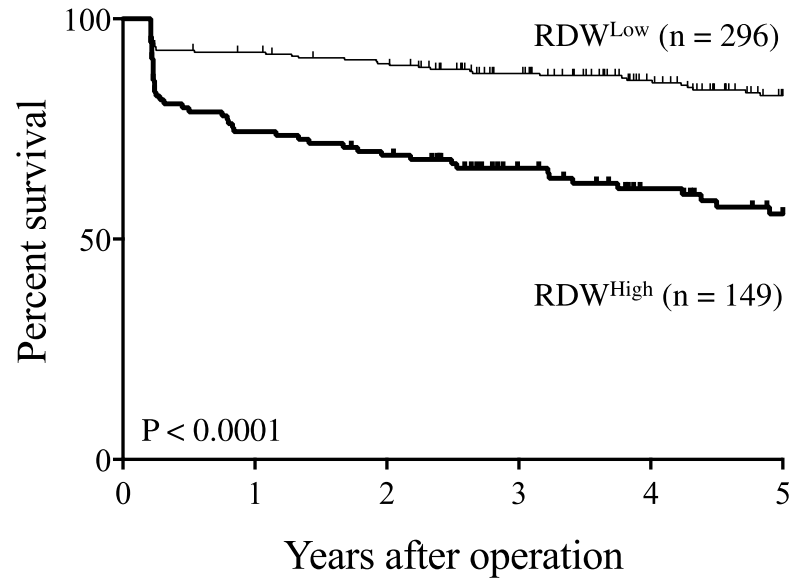

(b)

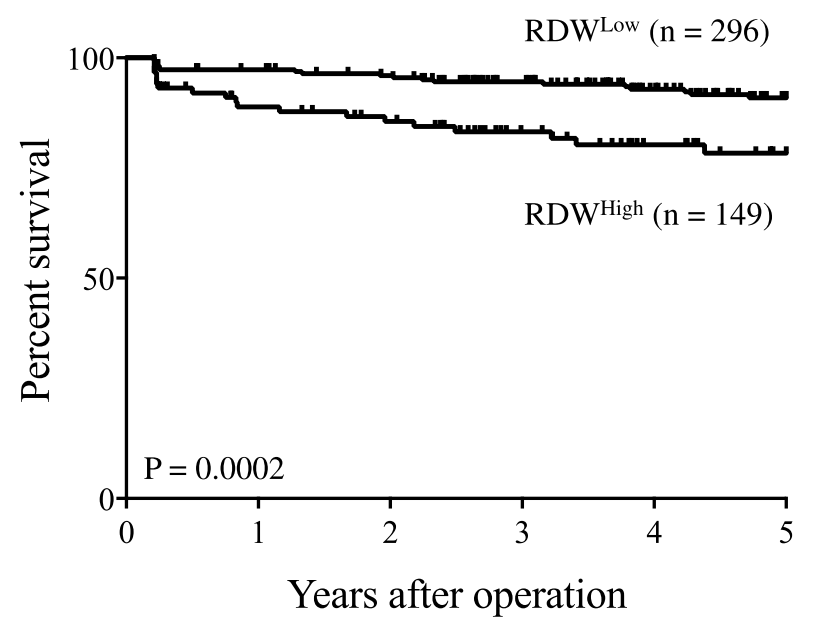

Fig. 3 a Overall survival (OS) curves by preoperative RDW. OS was significantly worse in RDW ${ }^{\text {High }}$ patients than in RDW ${ }^{\text {Low }}$ patients $(P<0.0001)$. $\mathbf{b}$ Disease-specific survival (DSS) curves by preoperative RDW. DSS was significantly worse in RDW ${ }^{\text {High }}$ patients than in RDW ${ }^{\text {Low }}$ patients $(P=0.0002)$

in GC patients under these situations. Although clinicians pay less attention to PDW than PC as a prognostic indicator, we found that the AUC of PDW for OS was higher than that of $\mathrm{PC}$, indicating that $\mathrm{PDW}$ is a more accurate prognostic indicator than $\mathrm{PC}$ in $\mathrm{GC}$ patients. In fact, we demonstrated that elevated PDW was closely related to poor prognosis in GC patients in this study. The close correlation between elevated PDW and poor prognosis was also reported in patients with esophageal cancer [20], hepatocellular carcinoma [21], and breast cancer [22]. On the other hand, Cheng et al. demonstrated that decreased PDW was significantly associated with poor disease free survival for early GC, which was totally opposite to our results [23]. In their study, they used median value of PDW as cut-off. On the other hand, we determined optimal cut-off value by using ROC analysis. Furthermore, they determined early GC patients, while we determined both early and advanced

Table 3 Univariate and multivariate analysis for overall survival of gastric cancer patients using Cox proportional hazard model and a stepwise procedure

\begin{tabular}{|c|c|c|c|c|c|c|}
\hline & \multicolumn{3}{|c|}{ Univariate } & \multicolumn{3}{|c|}{ Multivariate } \\
\hline & $P$ value & Hazard ratio & $95 \% \mathrm{Cl}$ & $P$ value & Hazard ratio & $95 \% \mathrm{Cl}$ \\
\hline Age $(\geq 70$ vs. $<70)$ & $<0.0001$ & 4.968 & $3.206-7.700$ & $<0.0001$ & 3.915 & $2.515-6.093$ \\
\hline Gender (male vs. female) & 0.1855 & 1.392 & $0.853-2.273$ & & & \\
\hline Tumor size ( $\geq 4 \mathrm{~cm}$ vs. $<4 \mathrm{~cm}$ ) & $<0.0001$ & 2.604 & $1.751-3.861$ & & & \\
\hline Histology (undifferentiated vs. differentiated) & 0.4867 & 1.105 & $0.776-1.703$ & & & \\
\hline Depth of invasion (T2/T3/T4 vs. T1) & $<0.0001$ & 2.599 & $1.750-3.858$ & & & \\
\hline Lymph node metastasis (present vs. absent) & $<0.0001$ & 3.096 & $2.090-4.584$ & 0.0042 & 1.923 & $1.229-3.010$ \\
\hline Lymphatic invasion (present vs. absent) & $<0.0001$ & 2.487 & $1.573-3.934$ & & & \\
\hline Vascular invasion (present vs. absent) & $<0.0001$ & 3.332 & $2.163-5.134$ & 0.0114 & 1.898 & $1.155-3.119$ \\
\hline Approach (open vs. laparoscopy) & $<0.0001$ & 3.140 & $1.857-5.309$ & 0.0238 & 1.888 & $1.088-3.275$ \\
\hline Gatrectomy (total vs. distal and proximal partial) & 0.0002 & 2.237 & $1.471-3.401$ & & & \\
\hline Lymph node dissection (D2 vs. D0/D1) & 0.0166 & 1.623 & $1.092-2.410$ & & & \\
\hline Adjuvant chamotherapy (present vs. absent) & 0.0034 & 1.939 & $1.245-3.018$ & & & \\
\hline Preoperative PDW (PDW ${ }^{\text {High }}$ vs. PDW ${ }^{\text {Low }}$ & 0.0020 & 1.900 & $1.266-2.853$ & 0.0009 & 2.031 & $1.338-3.082$ \\
\hline Preoperative RDW (RDW ${ }^{\text {High }}$ vs. RDW ${ }^{\text {Low }}$ ) & $<0.0001$ & 2.882 & $1.946-4.268$ & $<0.0001$ & 2.553 & $1.714-3.802$ \\
\hline
\end{tabular}

Cl confidence interval

See Table 1 for histology and the depth of invasion 


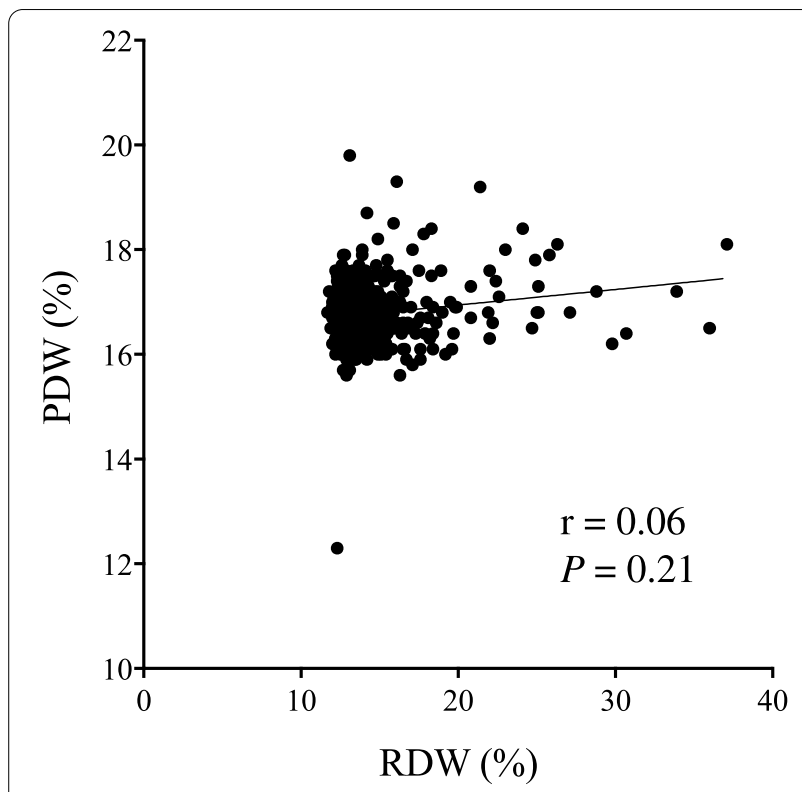

Fig. 4 a The correlation between PDW and RDW $(r=0.06, P=0.21)$

GC. These might make differences between our results and their ones.

Recent studies showed the close correlation between high RDW and poor prognosis in patients with lung cancer [24]. The iron deficiency anemia is often observed in GC patients because GC is associated with chronic blood loss, poor nutrition, and low iron absorption. Cancer-induced inflammation leads to inhibited response to erythropoietin, reduced iron release from reticuloendothelial macrophages, and shortened red blood cell survival. The number of immature red
Table 4 Multivariate analysis for overall survival of gastric cancer patients using Cox proportional hazard model and a stepwise procedure

\begin{tabular}{llll}
\hline & $P$ value & Hazard ratio & $\mathbf{9 5 \% ~ C l}$ \\
\hline $\begin{array}{l}\text { Age }(\geq 70 \text { vs. } \\
<70)\end{array}$ & $<0.0001$ & 3.922 & $2.519-6.107$ \\
$\begin{array}{l}\text { Lymph node } \\
\text { metastasis (pre- } \\
\text { sent vs. absent) }\end{array}$ & 0.0046 & 1.910 & $1.220-2.990$ \\
$\begin{array}{l}\text { Vascular inva- } \\
\text { sion (present vs. }\end{array}$ & 0.0079 & 1.948 & $1.191-3.187$ \\
$\begin{array}{l}\text { absent) } \\
\begin{array}{l}\text { Approach (open } \\
\text { vs. laparoscopy) } \\
\text { Combination of }\end{array}\end{array}$ & 0.0237 & 1.889 & $1.089-3.279$ \\
\begin{tabular}{l} 
PDW and RDW \\
\hline
\end{tabular} & $<0.0001$ & 2.292 & $1.697-3.096$ \\
\hline
\end{tabular}

$\mathrm{Cl}$ confidence interval

blood cells in the periphery increases under these situations, which results in high RDW. Therefore, high RDW is often observed in GC patients. The close correlations among RDW, inflammation, and nutritional status let us speculate that RDW could be a prognostic indicator in cancer patients, as both inflammation and poor nutritional status are often observed in cancer patients and worsen their prognosis. In fact, Cheng et al. reported preoperative RDW as prognostic indicator in GC patients [23]. We also demonstrated that high RDW was significantly related to poor prognosis of GC patients. Furthermore, multivariate analysis revealed that both PDW and RDW were independent prognostic indicators in GC patients. Since there was no statistically significant correlation between preoperative RDW

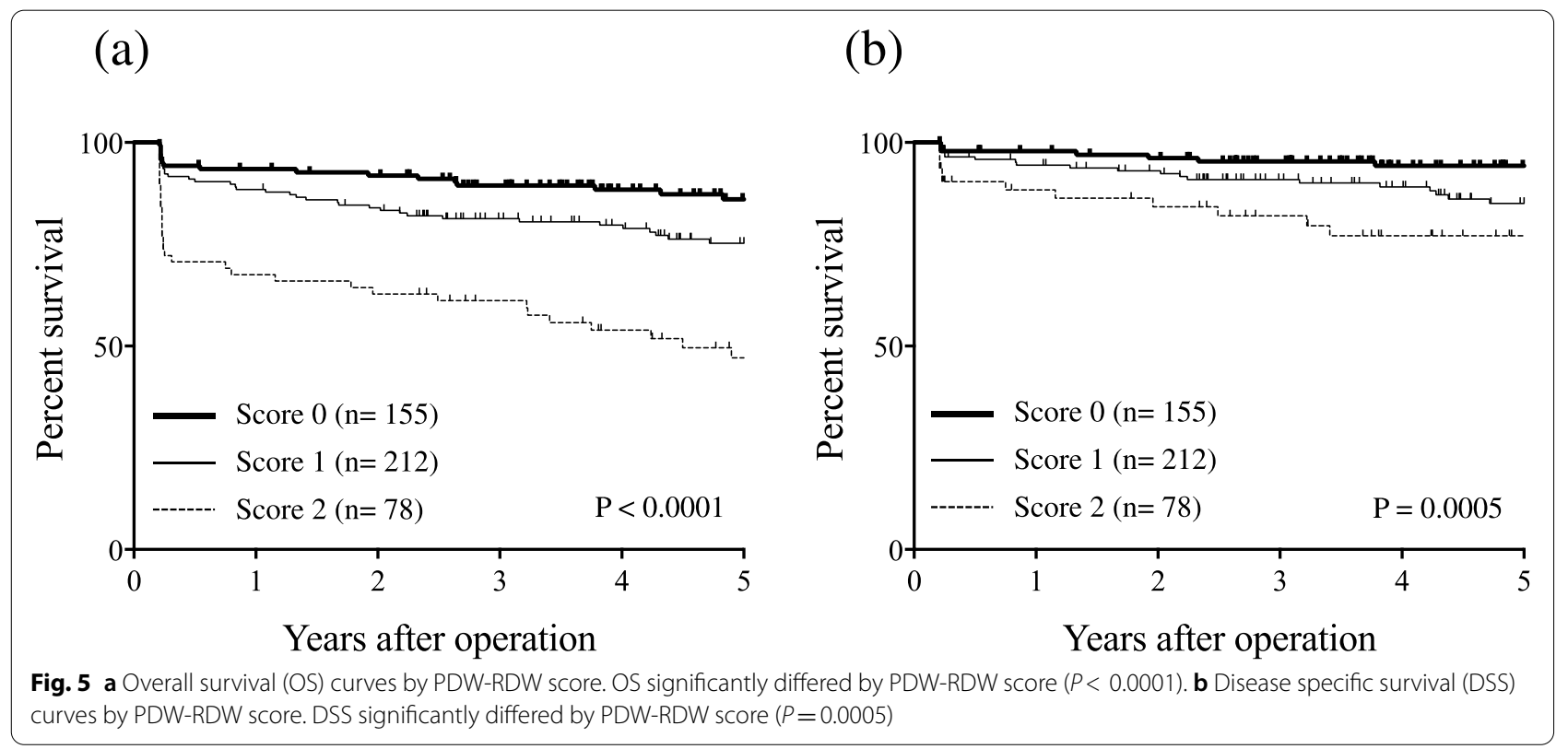


and PDW, we thought that the combination of PDW and RDW might be more useful than either indicator used alone. To confirm this possibility, we determined the prognostic significance of PDW-RDW score in this study and found that PDW-RDW score was more useful in predicting the prognosis of GC patients than single usage of either PDW or RDW alone. To our knowledge, this is the first study to demonstrate the prognostic significance of the combination of PDW and RDW in GC patients.

Our study had a few limitations. First, because it was retrospective, it was subject to bias. Second, the number of patients included in our study was small and the results must therefore be confirmed in a large-scale trial.

In conclusion, our study suggests the potential utility of combining PDW and RDW to predict prognosis in GC patients. Because they are obtainable from CBC data, the combination of PDW and RDW may be useful in managing GC patients in routine clinical settings.

\section{Abbreviations \\ CEA: Carcinoembryonic antigen; CBC: Complete blood count; DSS: Disease- specific survival; GC: Gastric cancer; IL-6: Interleukin-6; OS: Overall survival; PC: Platelet count; PD-ECGF: Platelet derived endothelial cell growth factor; PDW: Platelet distribution width; RDW: Red cell distribution width; ROC: Receiver operating characteristic.}

\section{Acknowledgments}

We thank Marla Brunker, from Edanz Group (www.edanzediting.com/ac) for editing a draft of this manuscript.

\section{Authors' contributions}

HS participated in the design of the study, interpretation of data, analysis, and drafting the article. SS, YS, KM, and TM collected data. YF revised the article. All authors approved the final version of the article.

\section{Funding}

The authors received no grants, equipment or funding for this study.

\section{Availability of data and materials}

The datasets generated during and analysed during the current study are not publicly available due to their containing information that could compromise the privacy of research participants but are available from the corresponding author on reasonable request.

\section{Declarations}

\section{Ethics approval and consent to participate}

All procedures followed were in accordance with the ethical standards of the responsible committee on human experimentation (institutional and national) and with the Helsinki Declaration of 1964 and later versions. This study was approved by Institutional Review Board of Tottori University Hospital (approval number: 1705A041), and informed consent of using clinical data for this study was obtained by the method of opt-out on the website from the patients according to instruction by ethical committee.

\section{Consent for publication}

Not applicable.

\section{Competing interests}

The authors declare that they have no competing interests.

\section{Author details}

'Department of Surgery, Japanese Red Cross Tottori Hospital, 117 Shotoku-cho, Tottori 680-8517, Japan. ${ }^{2}$ Division of Gastrointestinal and Pediatric Surgery, Department of Surgery, School of Medicine, Tottori University Faculty of Medicine, 36-1 Nishi-cho, Yonago 683-8504, Japan.

Received: 23 Auqust 2021 Accepted: 15 November 2021

Published online: 09 December 2021

\section{References}

1. Bath PM, Missouris CG, Buckenham T, MacGregor GA. Increased platelet volume and platelet mass in patients with atherosclerotic renal artery stenosis. Clin Sci (Lond). 1994;87(2):253-7.

2. Bath PM, Butterworth RJ. Platelet size: measurement, physiology and vascular disease. Blood Coagul Fibrinolysis. 1996;7(2):157-61.

3. Santimone I, Di Castelnuovo A, De Curtis A, Spinelli M, Cugino D, Gianfagna F, et al. White blood cell count, sex and age are major determinants of heterogeneity of platelet indices in an adult general population: results from the MOLI-SANI project. Haematologica. 2011;96(8):1180-8.

4. Forhecz Z, Gombos T, Borgulya G, Pozsonyi Z, Prohaszka Z, Janoskuti L. Red cell distribution width in heart failure: prediction of clinical events and relationship with markers of ineffective erythropoiesis, inflammation, renal function, and nutritional state. Am Heart J. 2009;158(4):659-66.

5. Patel KV, Ferrucci L, Ershler WB, Longo DL, Guralnik JM. Red blood cell distribution width and the risk of death in middle-aged and older adults. Arch Intern Med. 2009;169(5):515-23.

6. Douglas SW, Adamson JW. The anemia of chronic disorders: studies of marrow regulation and iron metabolism. Blood. 1975;45(1):55-65.

7. Ferrucci L, Guralnik JM, Woodman RC, Bandinelli S, Lauretani F, Corsi AM, et al. Proinflammatory state and circulating erythropoietin in persons with and without anemia. Am J Med. 2005;118(11):1288.

8. Sung H, Ferlay J, Siegel RL, Laversanne M, Soerjomataram I, Jemal A, et al. Global Cancer statistics 2020: GLOBOCAN estimates of incidence and mortality worldwide for 36 cancers in 185 countries. CA Cancer J Clin. 2021;71(3):209-49.

9. Japanese Gastric Cancer Association. Japanese classification of gastric carcinoma: 3rd English edition. Gastric Cancer. 2011;14(2):101-12.

10. Ishikawa F, Miyazono K, Hellman U, Drexler H, Wernstedt C, Hagiwara $\mathrm{K}$, et al. Identification of angiogenic activity and the cloning and expression of platelet-derived endothelial cell growth factor. Nature. 1989;338(6216):557-62.

11. Karpatkin S, Pearlstein E. Role of platelets in tumor cell metastases. Ann Intern Med. 1981:95(5):636-41.

12. Gislason T, Nou E. Sedimentation rate, leucocytes, platelet count and haemoglobin in bronchial carcinoma: an epidemiological study. Eur J Respir Dis. 1985;66(2):141-6.

13. Cox G, Walker RA, Andi A, Steward WP, O'Byrne KJ. Prognostic significance of platelet and microvessel counts in operable non-small cell lung cancer Lung Cancer. 2000;29(3):169-77.

14. Gu ML, Yuan CJ, Liu XM, Zhou YC, Di SH, Sun FF, et al. Pre-treatment elevated platelet count associates with HER2 overexpression and prognosis in patients with breast Cancer. Asian Pac J Cancer Prev. 2015;16(13):5537-40.

15. Xin-Ji Z, Yong-Gang L, Xiao-Jun S, Xiao-Wu C, Dong Z, Da-Jian Z. The prognostic role of neutrophils to lymphocytes ratio and platelet count in gastric cancer: a meta-analysis. Int J Surg. 2015;21:84-91.

16. Long Y, Wang T, Gao Q, Zhou C. Prognostic significance of pretreatment elevated platelet count in patients with colorectal cancer: a meta-analysis. Oncotarget. 2016;7(49):81849-61.

17. Chadha AS, Kocak-Uzel E, Das P, Minsky BD, Delclos ME, Mahmood U, et al. Paraneoplastic thrombocytosis independently predicts poor prognosis in patients with locally advanced pancreatic cancer. Acta Oncol. 2015;54(7):971-8

18. Refaai MA, Phipps RP, Spinelli SL, Blumberg N. Platelet transfusions: impact on hemostasis, thrombosis, inflammation and clinical outcomes. Thromb Res. 2011;127(4):287-91. 
19. Ikeguchi M, Hatada T, Yamamoto M, Miyake T, Matsunaga T, Fukumoto Y, et al. Serum interleukin-6 and -10 levels in patients with gastric cancer. Gastric Cancer. 2009;12(2):95-100.

20. Matsunaga T, Saito H, Fukumoto Y, Shimizu S, Kono Y, Murakami Y, et al. The postoperative platelet distribution width is useful for predicting the prognosis in patients with esophageal squamous cell carcinoma. Surg Today. 2020;50(2):123-33.

21. Zuo X, Kong W, Feng L, Zhang H, Meng X, Chen W. Elevated platelet distribution width predicts poor prognosis in hepatocellular carcinoma. Cancer Biomark. 2019;24(3):307-13.

22. Huang Y, Cui MM, Huang YX, Fu S, Zhang X, Guo H, et al. Preoperative platelet distribution width predicts breast cancer survival. Cancer Biomark. 2018;23(2):205-11.

23. Cheng S, Han F, Wang Y, Xu Y, Qu T, Ju Y, et al. The red distribution width and the platelet distribution width as prognostic predictors in gastric cancer. BMC Gastroenterol. 2017;17(1):163.

24. Koma Y, Onishi A, Matsuoka H, Oda N, Yokota N, Matsumoto Y, et al. Increased red blood cell distribution width associates with cancer stage and prognosis in patients with lung cancer. PLoS One. 2013;8(11):e80240.

\section{Publisher's Note}

Springer Nature remains neutral with regard to jurisdictional claims in published maps and institutional affiliations. 